\title{
Correlations between energy economy and housing market prices in the EU-impacts on future sustainability
}

\author{
Maria Alexandra MAASSEN \\ The Bucharest University of Economic Studies, Bucharest, Romania \\ maria.nichifor@fabiz.ase.ro
}

\begin{abstract}
The global economic system is facing multiple challenges in terms of social development, technology and innovation, as well as sustainability needs. As a result, the value of existing assets is changing globally depending on the scarcity, necessity and effects on the business field leading to increased prices of traditional sources of energy and increased competition in the economic field. Thus, the EU energy market has progressed in reducing its dependence on external energy sourcing, by increasing production of renewable energy, such as wind or solar, as well as by further integration of the electric grid. Based on the Pearson coefficient this article intends to research the correlations between the economic, energy and house prices in recent years and the future possible impacts depending on their evolution. For example, gas prices in the past decade increasing household costs in most countries due to the dependence on third parties for energy, lead to the need of increasing the share of renewable energy in total energy consumption, which have consequently decreased electricity prices since 2008. However, this development has still not solved the additional costs issue of households due to the new technologies implemented although wind and solar energy receive in general low margins. Such energy issues, as well as the increased housing prices after the financial crisis in 2008 have caused on their own an additional burden on the economy and households spending income in the next years following.
\end{abstract}

Keywords: energy, correlations, house price index, renewable energy, economy.

\section{Introduction}

In recent years the economic and energy fields are encountering more frequent connecting variables, as the pressure of substituting traditional, polluting sources of traditional energy with renewable energy is increasing, as well as the pressure of maintaining an economic competitive environment worldwide. Today, the necessity of maintaining high sustainability levels, socially and economically, due to the challenges of climate changing, limitation of energy resources and the obligation of lowering pollution levels have become a part of the concept of being market competitive. If before the year 2000 sustainability measures were considered an optional strategy of companies and society, today it is a mandatory requirement, also included in regulatory frameworks, such as the European Union 2020 objective, in order to develop the competition in the business field and to ensure favorable, long term living conditions globally. Thus, in the last decade the installments of renewable energy have increased exponentially.

According to the International Renewable Energy Agency IRENA (2017) in 2015 renewable energy power generating capacity represented more than 1,811 GW, while the renewable power capacity represented $61 \%$ of all new power generating capacity added globally. The European Union energy objective 2020 of having $20 \%$ of the energy consumption covered from renewable energy sources, has led to increased efforts of sustainability, through the installment of renewable energy capacities, but 
also through measures of reducing other forms of waste. While the gross domestic product increased in the European Union since 2010 until 2015, according to Eurostat data (2017), other factors affecting the living conditions of the population and the possibility of new renewable energy capacities have also changed, such as electricity prices of consumers, depending on their nature, house prices, minimum wages and energy intensity.

In the present article the main objective is to study the correlation between nine main economic, energy and house prices variables for European Union countries and their possible impacts on sustainability efforts for the future years. The selected indicators are: the gross domestic product, the minimum wage, the energy intensity, the electricity prices of domestic consumers, the electricity prices of industrial consumers, house price index, gross inland renewable energy consumption, inequality of income distribution.

\section{Literature review}

Correlations between different indicators of the economy have been studied by several authors in the scientific literature before, however correlations between economic and energy indicator remain a contemporary subject of observation, as changes in the field are continuous in present time, respectively as new renewable energy capacities are installed and replacing consequently traditional sources of energy and other indicators also evolve depending on social, geographical and economic factors of influence.

For example, Dima and Ghinea (2016) proposed a correlation of university curricula with the international labour market needs and requirements, which connects the educational field with the practical labour market needs. Another study of Dima and Vasilache (2013) also focused on the study of strategies in order to balance ethical, social and environmental concerns with corporate requirement, practically the educational and environmental fields with corporation needs.

Chima (2007) studied the correlation between energy prices and energy consumption and GDP in the USA and observed a high sensitivity of energy consumption to energy prices, which in turn also impacted the GDP. Furthermore, Valadez (2010) implied that a quarterly change in the housing price index may yield a quarterly change in Real GDP for the case of US before, during and after the financial crisis in 2007 through the use of correlations. Studies in recent years focused more frequently on energy statistics, as this business field is increasing in importance due to new sustainability standards that oblige in the next years a certain quota of renewable energies for the energy consumption.

As shown in Figure 1, the gross domestic product (GDP) fluctuated in the last years reaching a peak of 105,4 in 2015, while the maximum decrease was in 2009 with a level of 97.9 coinciding with one of the years of the financial crisis in the region. 


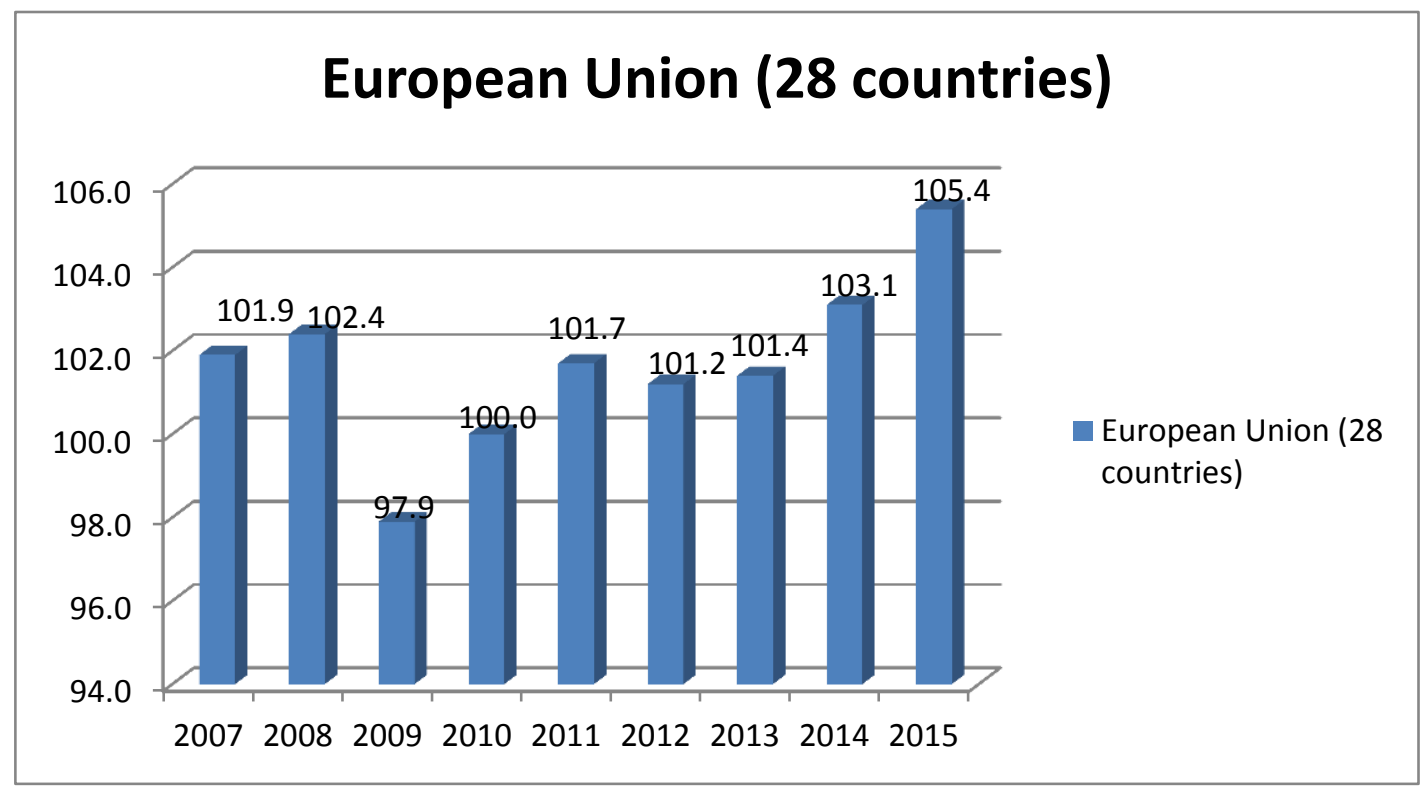

PICBE $\mid 47$

Figure 1. GDP according to market prices in the European Union 2007-2015 index $\mathbf{2 0 1 0}=\mathbf{1 0 0}$

Source: Eurostat (2017).

While the GDP has a growth tendency over the years in the European Union especially since 2010, the energy intensity, indicating the energy consumed, had a decrease tendency, as shown in Figure 2. As shown below, overall in the European Union the consumption of energy decreased constantly over the past years, indicating more efficiency in the energy consumption.

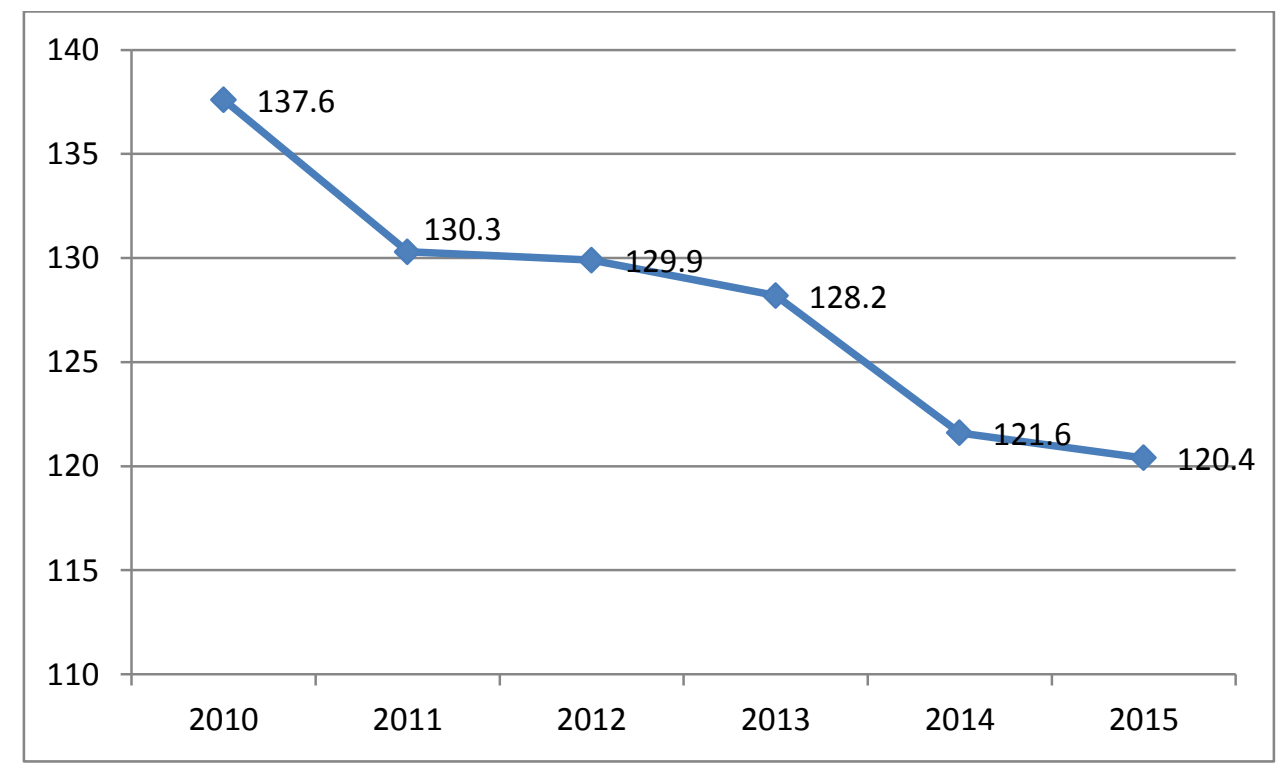

Figure 2. Energy intensity in the European Union 2007-2015 (kg of oil equivalent per 1000 EUR)

Source: data Eurostat (2017). 
At the same time with increasing installments of renewable energy, $61 \%$ of all new power generating capacity added globally representing green sources of energy, the renewable energy consumption at the level of the European Union constantly increased since 2006, in 2015 reaching 210037 thousand tons of oil equivalent, see Figure 3, this trend of increasing levels still continues today. The renewable energy consumption indicates the progress in using green sources of energy for covering consumers' needs of energy and in the replacement of traditional, polluting sources of energy. This also implies for the future less dependency on sources such as petrol or coal and thus less dependency for energy among the states, however this replacement of old sources of energy being a middle to long term process.

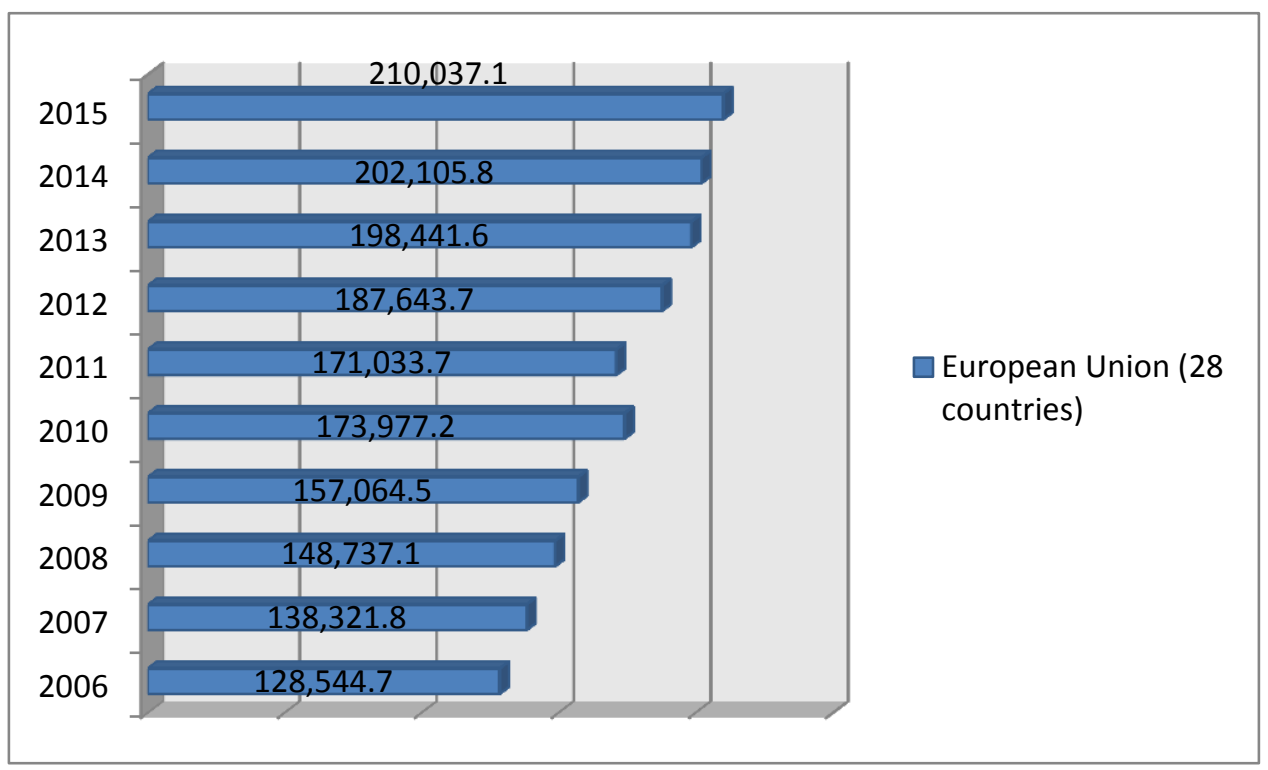

Figure 3. Gross inland renewable energy consumption 2006-2015 (Thousand tons of oil equivalent (TOE))

Source: data Eurostat (2017).

\section{Methodology}

In order to analyze the situation of the European Union countries (excepting Greece and Iceland for which certain data was not available), the Pearson coefficient was used to determine the correlations between the multiple variables chosen for the study. For this analysis, nine economic and energy indicators from the year 2015 were chosen for the following countries: United Kingdom, Norway, Sweden, Finland, Romania, Portugal, Slovakia, Slovenia, Poland, Austria, the Netherlands, Malta, Hungary, Luxembourg, Latvia, Lithuania, Cyprus, Italy, Croatia, France, Spain, Ireland, Estonia, Germany, Denmark, the Czech Republic, Bulgaria, Belgium. The selected energy indicators for 2015 included: energy intensity of the countries, gross inland renewable energy consumption, electricity prices for domestic consumers, electricity prices for industrial consumers, energy savings. The economy indicators of the same year, that were chosen, referred to: gross domestic product (GDP), inequality of income distribution, annual minimum wage by country. The house price index was also taken into consideration for the correlation calculation. 
The Pearson coefficient formula is determined by using the difference mean minus mode and the standard deviation, as follows (Sharma, 2007):

$\frac{E[(X-E(X))(Y-E(Y))]}{\sigma X \sigma Y}$

In the previously listed formula $\mathrm{E}(\mathrm{X}), \mathrm{E}(\mathrm{Y})$ are means of the factors $\mathrm{X}, \mathrm{Y}$ and the division factors refer to the standard deviations of $\mathrm{X}$ and $\mathrm{Y}$.

\section{Findings and results}

The following correlations were revealed after the calculations were performed:

Table 1. Correlations between economy, housing and energy indicators for EU countries 2015 (except for Greece and Iceland)

\begin{tabular}{|l|l|}
\hline Indicators correlated & Pearson coefficient value \\
\hline $\begin{array}{l}\text { Energy intensity (EI)-electricity prices for } \\
\text { domestic consumers (EPDC) }\end{array}$ & -0.529 \\
\hline $\begin{array}{l}\text { Energy intensity(EI)- Minimum wages } \\
\text { (MWg) }\end{array}$ & -0.669 \\
\hline $\begin{array}{l}\text { Gross inland renewable energy } \\
\text { consumption (RWC)-Energy savings (ES) }\end{array}$ & 0.878 \\
\hline $\begin{array}{l}\text { Inequality of income distribution (IID)- } \\
\text { Minimum wage (MWg) }\end{array}$ & -0.408 \\
\hline $\begin{array}{l}\text { Electricity prices for domestic consumers } \\
\text { (EPDC)-Electricity prices for industrial } \\
\text { consumers (EPIC) }\end{array}$ & 0.589 \\
\hline $\begin{array}{l}\text { House price index (HPI)-Electricity prices } \\
\text { for industrial consumers (EPIC) }\end{array}$ & -0.4665 \\
\hline $\begin{array}{l}\text { Energy intensity (EI)-Inequality of } \\
\text { income distribution (IID) }\end{array}$ & 0.378 \\
\hline $\begin{array}{l}\text { House price index (HPI)-Gross domestic } \\
\text { product (GDP) }\end{array}$ & 0.378 \\
\hline \multicolumn{2}{|c|}{ Source: Authors' own research based on data from Eurostat (2017), Thelocalit (2017), } \\
Wageindicator (2017)
\end{tabular}

For this study the indicators were measured as follows. The electricity prices for industrial consumers are measured in Euro, as well as those for electricity prices for domestic consumers or the household sector. Inequality in income distribution of a country may be usually considered an indicator of living conditions in the respective region, besides the GDP per capita, such as in the case that a lower inequality in income distribution would mean better economic condition for the population of the country, while a high inequality income distribution are often linked to high poverty, crime and social exclusion, on the other hand stimulating innovation, learning new skills and improving work (Eurostat, 2017). Energy intensity was calculated as Gross inland consumption of energy divided by GDP (kg of oil equivalent per 1000 EUR), 
according to Eurostat statistics (2017). Gross inland renewable energy consumption was measured in thousand tons of oil equivalent as per annual data. House price index was the average annual index, where 2010 was considered basic year, also here the evolution of 5 years after the financial crisis. This indicator might evolve differently in the next years depending on further effects o the financial crisis and further economic developments. Gross domestic product (GDP) represents the value of final goods and services produced in a year. In this article I chose the GDP where year $2010=100$, as the evolution of five years after the period of the financial crisis. It is also possible that certain turbulences caused by the financial crisis that can evolve differently in the next years as well.

The highest correlation was found between gross inland renewable energy consumption and energy savings, namely a strong positive correlation of 0.878 . This correlation indicates the tendency that the countries with a higher consumption of renewable energy tend to have more energy savings. For example, Germany, which had the highest renewable energy consumption 38354.2 thousand tons of oil equivalent also had the highest energy savings (292.9), followed by Italy and France. On the contrary, Slovenia with one of the lowest renewable energy consumptions (1056 thousand tons of oil equivalent) had one of the lowest energy savings (6.5), statistical information according to Eurostat (2017).

The second highest correlation, this time, a negative one, refereed to the one between energy intensity and minimum wages (-0.669). This was an average correlation and indicated the tendency that countries with lower minimum wages tended to have a higher energy intensity, while countries with higher minimum wages tended to have a lower energy intensity, thus using energy more efficiently. The higher the energy intensity is, the more energy is used. For example, in Bulgaria and Romania, where minimum wages for 2015 were estimated at approximately 184 Euro in Bulgaria and 217,5 Euro in Romania, thus representing the lowest minimum wages in the European Union, the energy intensity was high (448,5 in Bulgaria and 226,7 in Romania), see Figure 4 below. This meant these two countries tended to consume energy more inefficiently than other countries with higher levels of minimum wages. This is the case of countries like, Denmark (minimum wage 2015 estimated at 2990 Euro and an energy intensity level of 65.1), Luxembourg (minimum wage 2015 estimated at 1922.26 Euro with an energy intensity level of 90.7), all the statistical data according to Eurostat (2017). This correlation could be explained by the fact that countries with better minimum living conditions tend to focus their efforts more on an efficient energy consumption and on the efforts of minimizing it. 


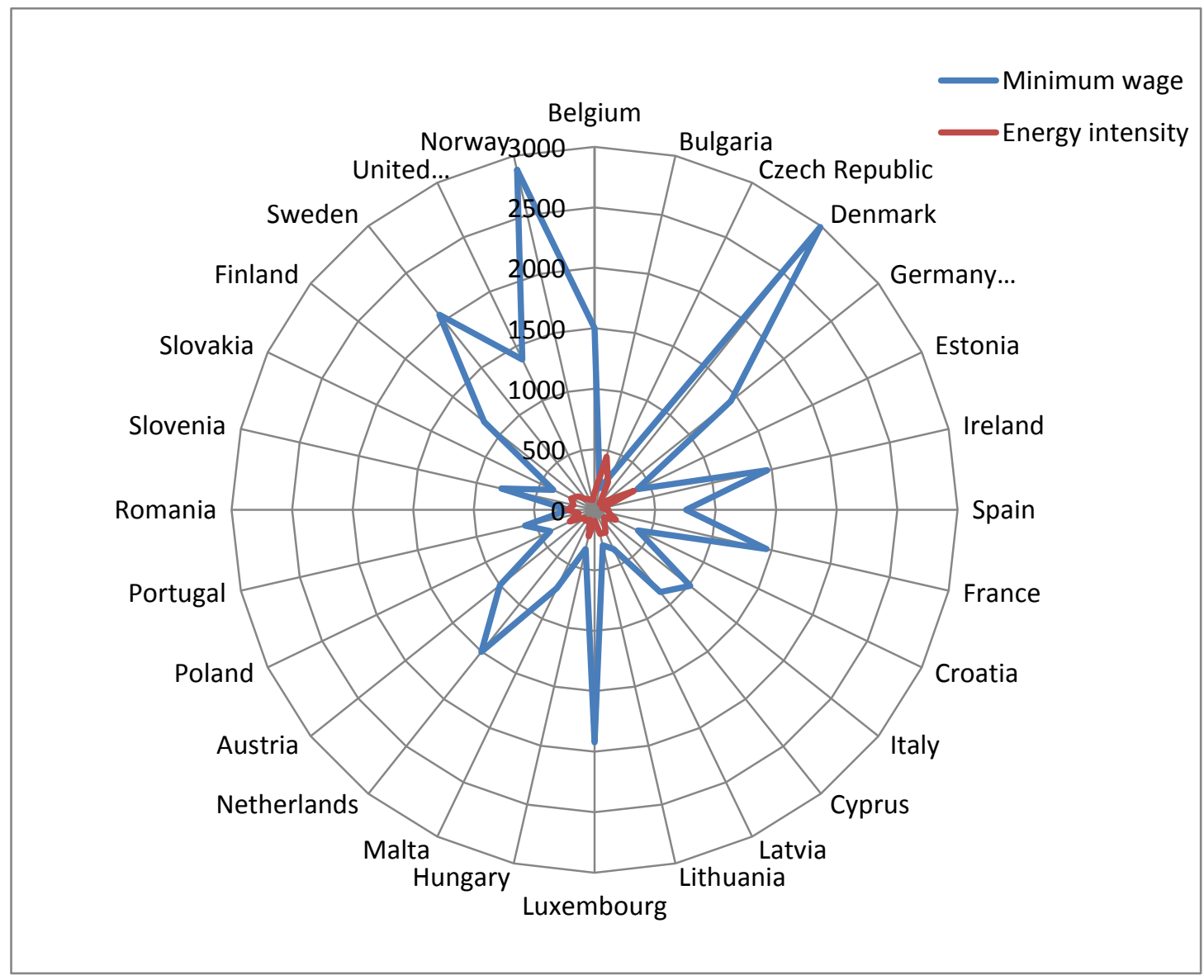

PICBE $\mathbf{5 1}$

Figure 4. Radar chart of minimum wage-energy intensity European Union (except for Greece and Iceland) 2015

Source: Author's own research based on statistical data Eurostat (2017).

The third correlation was an average positive correlation between electricity prices for domestic consumers (EPDC) and electricity prices for industrial consumers (EPIC) with a value of 0.589 . That indicated countries with a higher electricity price for domestic consumers tended to have also a higher electricity price for industrial consumers, such as in the cases of Germany, Ireland and the United Kingdom, that offered higher electricity prices to domestic consumers and higher electricity prices to industrial consumers as opposite to the cases of countries, such as Denmark, Finland, Romania, Lithuania, see Figure 5.

Another average correlation, respectively a negative correlation was found between energy intensity and electricity prices of domestic consumers (-0.529). This correlation refers to the tendency in countries with a high energy intensity to have less high electricity prices for domestic consumers, while countries with a lower energy intensity having a higher electricity price for domestic consumers. Thus, although being more efficient in terms of energy consumption, the countries with a lower energy intensity also maintain higher electricity prices for their households in comparison to the ones with high energy intensity. For example, in Germany in 2015 where energy intensity was low (112.6) the electricity price for domestic consumers 
was estimated at 0.14, while in Bulgaria, that had a high energy intensity level 448.5 the electricity price for domestic consumers was estimated at a level of 0.07, according to data from Eurostat (2017).

The last average correlation was the one between house price index (HPI)-Electricity prices for industrial consumers (EPIC) -0.4665, referring to the tendency of countries with a higher price index to have a lower electricity price for industrial consumers, PICBE 52 such as Germany HPI-119.3 with an EPIC of 0.06 in comparison to the Netherlands with an HPI-89,74 with an EPIC of 0.0767.

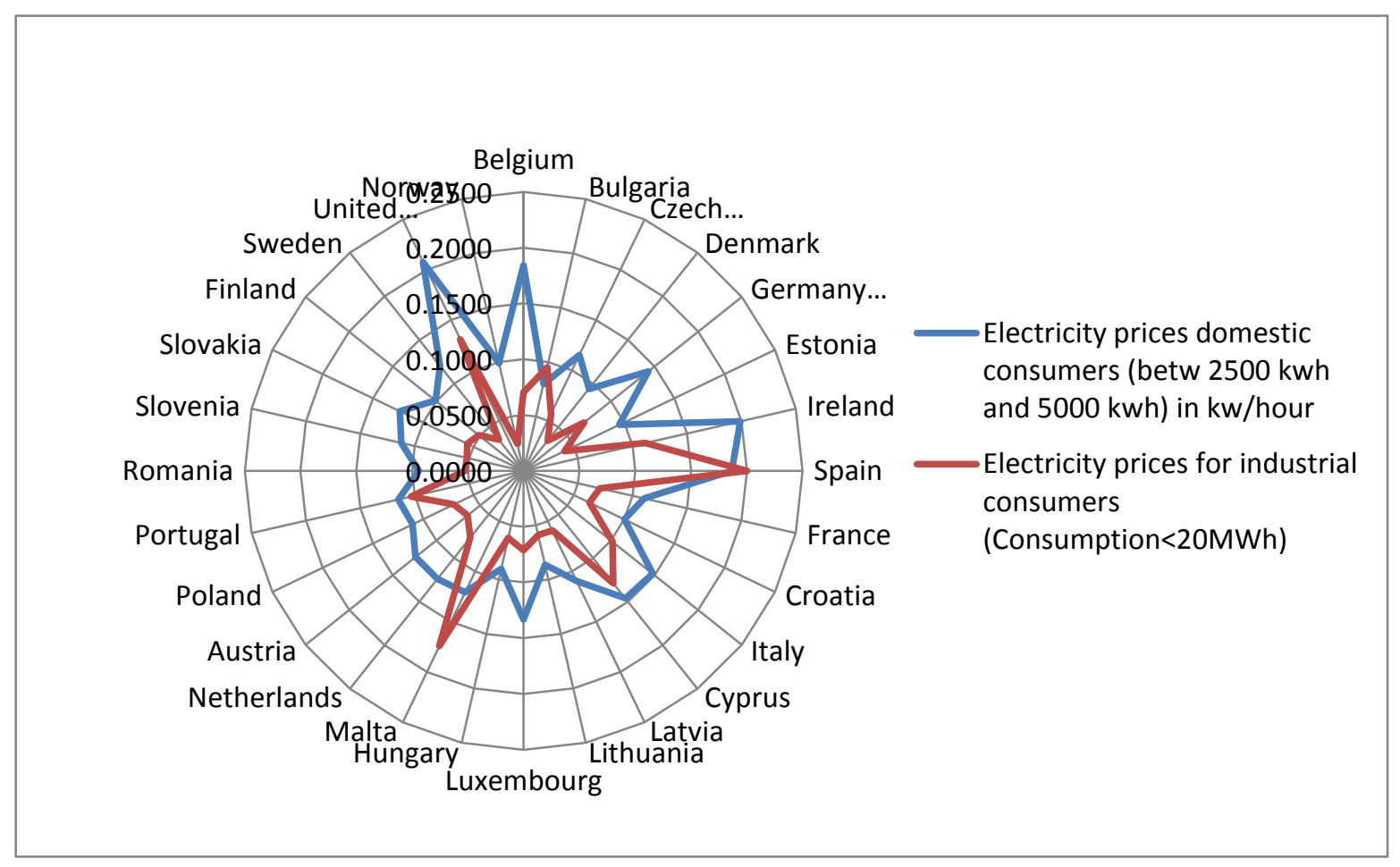

Figure 5. Radar chart of electricity prices domestic consumers-electricity prices industrial consumers European Union (except for Greece and Iceland) 2015

Source: Author's own research based on statistical data Eurostat (2017).

The house price index had a low positive correlation with the GDP (0.378), but other lower correlation values to the other indicators taken into account. Other correlations that were found had minimum values, thus being not concluding for the study, such as energy intensity (EI) and inequality of income distribution (IID).

\section{Conclusion}

In conclusion countries with better living conditions, in terms of ensured minimum wages tended to consume energy more efficiently as shown by the correlation between these two indicators with a level of -0.669 . Thus, countries with a better financial situation in terms of minimum wages tend to have a higher preoccupation for lowering their energy intensity and consuming less energy. The highest positive obtained correlation revealed the tendency of countries in the European Union with a 
high level of renewable energy consumption to have to save more energy. Another unexpected result was that of a negative correlation between the energy intensity and electricity prices for domestic consumers, implying the higher the energy intensity, thus the less efficient the energy consumption, the tendency of having lower electricity prices for domestic consumers.

Although overall the European Union has made significant progress in the energy efficiency, in terms of lowering energy intensity, increasing renewable energy consumption and also in terms of economic development, certain regions should concentrate their efforts towards energy consumption efficiency. Countries like Bulgaria , Croatia, Latvia, Lithuania, Poland, Estonia, Hungary, the Czech Republic and Romania, having a high energy intensity factor of over 194 (Bulgaria reaching the peak of 448,5), should implement strategies of lowering the energy consumption at household level and industrial level. Although all countries of the European Union have made significant progress in the installment and consumption of renewable energy, proving the quality of this type of energy, the risk of energy waste still remains an issue that can burden the economy.

Solutions for increasing energy savings and minimizing energy waste, leading to a higher supply of energy, reduced energy inefficiency and thus a better sustainability level in the economy, include education of population in the direction of sustainability, factor that has already started to be implemented at household level, but also in corporate social responsibility measures of all company. Furthermore, regulations, rewards and involvement of the citizens in the planning of energy and renewable energy projects and decisions may increase consciousness on the need of energy savings. The European Union 2020 objective of covering 20\% of the energy consumption from renewable energy sources is a compulsory strategy to all members of the region and thus, a motivator in the process of developing alternative green sources of energy. A significant progress in this field was done by countries in Eastern Europe, such as Romania, that has a comparable level of renewable energy, especially in terms of wind energy to the Netherlands.

For future research another objective would be to study the evolution of the selected factors of the present study depending on the market evolution, but also in correlation with other factors in the European Union and globally. As new sources of energy will prevail in the future and economic systems are encountering significant changes in different regions, these indicators might be changed for the next period and reveal other types of connections depending on social, energy and economic factors.

\section{References}

Chima, C.M. (2007). Intensity Of Energy Use In The U.S.A.: 1949 - 2003, Journal of Business \& Economics Research , 5(11), 17-30.

Dima, A. M., Ghinea, V. (2016). Conference: 12th European Conference on Management, Leadership and Governance (ECMLG) Location: Natl Univ Polit Studies \& Publ Adm, Coll Management, Bucharest, ROMANIA Date: November 10-11, 2016. 
Dima, A.M., Vasilache, S.N. (2013). Principles and strategies to balance ethical, social and environmental concerns with corporate requirements, Book Series: Advances in Sustainability and Environmental Justice, 12, 51-66.

Eurostat, (2017). Retrieved from: http://ec.europa.eu/eurostat/statisticsexplained/index.php/Income_distribution_statistics.

Eurostat. (2017). Retrieved from http://ec.europa.eu/eurostat/data/database?p_p_id

PICBE 54 =NavTreeportletprod_WAR_NavTreeportletprod_INSTANCE_nPqeVbPXRmWQ \&p_p_lifecycle $=0 \&$ p_p_state $=$ normal\&p_p_mode $=$ view $\&$ p_p_col_id $=$ column $-2 \& p$ _p_col_count=1.

Fischer, R. (2017). What Is Minimum Wage In European Union 2015. Retrieved from https://www.reinisfischer.com/what-minimum-wage-european-union-2015.

IRENA. (2017). Retrieved from http://www.irena.org/DocumentDownloads/Publicat ions/IRENA_REthinking_Energy_2017.pdf.

Sharma, J.K. (2007). Business statistics. Delhi: Dorling Kindersley.

Thelocalit. (2017). Retrieved from https://www.thelocal.it/jobs/article/italy-plansnational-minimum-wage.

Valadez, R.M. (2010). The housing bubble and the GDP: a correlation perspective, Journal of Case Research in Business and Economics, 1-18.

Wageindicator. (2017). Retrieved from Http://www.wageindicator.org/main/salary /minimum-wage/cyprus/cyprus-minimum-wage-faq. 